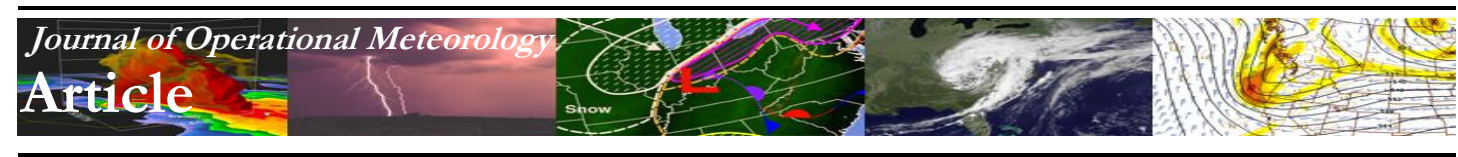

\title{
Reflectivity Vortex Hole in a Tornadic Supercell
}

\author{
CHAUNCY J. SCHULTZ \\ National Weather Service, Billings, Montana
}

(Manuscript received 25 June 2013; review completed 20 February 2014)

\begin{abstract}
The Weather Surveillance Radar-1988 Doppler (WSR-88D) at Thedford, Nebraska, detected a distinct reflectivity minimum in the hook echo of a tornadic supercell over north-central Nebraska on 11 August 2011. This "eye-like" feature was co-located with a tornadic vortex signature and was detectable to an altitude exceeding $8 \mathrm{~km}$ above ground level. A literature review of eye-like features in radar imagery in association with tornadic storms revealed that these signatures have been documented since the 1950s, but may have only recently become more commonly observed by WSR-88Ds with the change to super-resolution grid spacing. The reflectivity vortex hole observed on 11 August 2011 was analyzed using both constantelevation and three-dimensional radar imagery. Polarimetric radar data from WSR-88Ds in close proximity to four prominent tornadoes in May and June 2013 revealed at least brief reflectivity vortex holes with each of those cases, and suggested that recognition of vortex holes by meteorologists may supplement information from polarimetric tornadic debris signatures.
\end{abstract}

\section{Introduction}

An intense supercell over north-central Nebraska on the evening of 11 August 2011 produced an interesting and unique "eye" within its hook echo during tornadogenesis. This feature was observed in close proximity to the Weather Surveillance Radar-1988 Doppler (WSR-88D) at Thedford, Nebraska (KLNX), at a distance of approximately $28 \mathrm{~km}(15 \mathrm{n} \mathrm{mi})$. Warning meteorologists working the event had not previously encountered such a feature and were left to determine whether or not the signature was meaningful to their decision-making process.

Although warning meteorologists considered the feature observed on 11 August 2011 as unusual, observations of a miniature eye in the center of a tornado cyclone date back to the 1950s (Fujita 1958). More recently, the 3 May 1999 Oklahoma City, Oklahoma, tornado prominently displayed a similar weak echo eye in 50-m resolution data from the Doppler on Wheels (DOW) radar (Burgess et al. 2002). Lemon and Umscheid (2008) suggested that the weakreflectivity echo column observed by the WSR-88D with the prolific Greensburg, Kansas, tornadic supercell on 4 May 2007 was the same feature as the eye observed with the Oklahoma City, Oklahoma, tornado. This feature was called a reflectivity vortex hole by Lemon and Umscheid (2008). Apparently the KLNX WSR-88D reflectivity imagery associated with the supercell near Purdum, Nebraska, on 11 August 2011 also contained one of these vortex holes.

Polarimetric tornadic debris signatures (TDSs) and reflectivity "debris balls" can be used to detect tornadoes while they are producing damage (e.g., Ryzhkov et al. 2005; Bunkers and Baxter 2011). However, operational meteorologists also may encounter "eyelike" features in reflectivity data and should be aware of common nomenclature to describe the signature, its potential cause(s), and implications for the warning decision-making process, which may include increased confidence in a tornado even when no significant damage is occurring. The present study seeks to document and analyze the vortex hole observed in north-central Nebraska on 11 August 2011 with the purpose of aiding meteorologists in recognizing this important feature and taking appropriate actions. Previous research on eye-like features associated with tornadic storms is discussed in section 2. The data and methods used in this study are provided in section 3, and the analysis of the 11 August 2011 reflectivity vortex hole is presented in section 4 . In section 5 , four other reflectivity vortex holes observed with polarimetric WSR-88Ds are briefly examined and operational implications of 
vortex holes are discussed. The study is summarized in section 6.

\section{History of "eyes" in radar observations of torn- adic storms}

The presence of eye-like features in radar images was first discussed by Fujita (1958) when he described the miniature eye that appeared as a hole at the center of the tornado cyclone in radar film pictures of the Champaign, Illinois, tornado on 9 April 1953. Additional observations of eyes in the center of tornado cyclones were provided in Fujita (1965a). Several more radar-film examples were provided by Fujita (1965b), where the eye was defined as the echo-free area around the circulation axis with a diameter ranging from only 1 to $6 \mathrm{~km}(0.5$ to $3 \mathrm{n} \mathrm{mi})$-in contrast to the larger area surrounding the hook echo referred to as "the vault" by Browning (1965). In addition, Fujita (1981) showed a prominent eye in a Weather Surveillance Radar-1957 (WSR-57) reflectivity image of the infamous Grand Island, Nebraska, tornadoes of 3 June 1980 (Fig. 1).
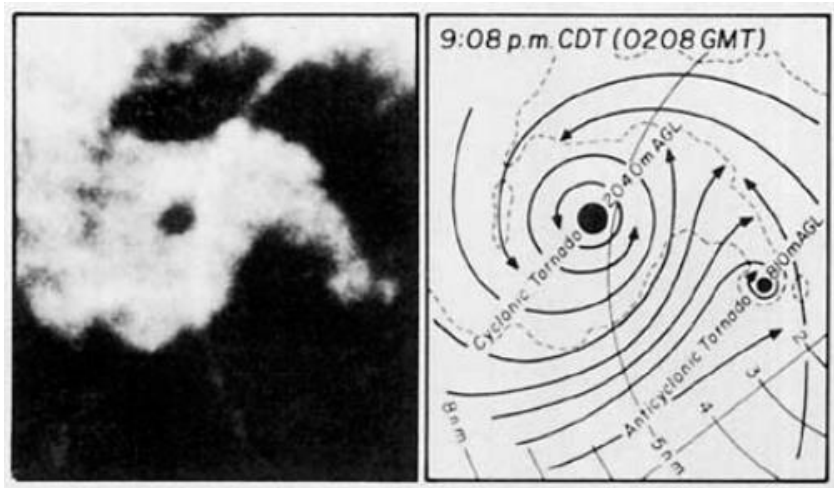

Figure 1. Figure 12 from Fujita (1981), showing a WSR-57 reflectivity image with a pronounced eye and an accompanying analysis of cyclonic and anticyclonic tornadoes at Grand Island, NE, on 3 June 1980. Click image for an external version; this applies to all figures hereafter.

Wakimoto and Martner (1992) combined radar observations of a weak-echo hole (WEH), or eye, within the hook of a tornadic supercell near Denver, Colorado, on 2 July 1987 with ground survey results and suggested that the WEH coincided with the location of the tornado. The WEH in Wakimoto and Martner (1992) grew upward with time, producing "a sharp tunnel of low reflectivity that extended well into the cloud," which they theorized to be caused by the centrifuging of large raindrops away from the center of the rotational axis. Dowell et al. (2005) studied the movement of hydrometeors and debris in tornadoes using numerical models and their results also suggested that the appearance of eyes in reflectivity data likely is caused by the centrifuging of radar scatterers.

Burgess et al. (2002) noted that high-resolution radar data like that from the DOW actually reveal a reflectivity minimum or eye with tornadoes on a regular basis. Wood et al. (2005) stated that such eyes typically are not visible by WSR-88D radars because they usually are farther away from tornadoes than are mobile radars like the DOW. One example of an eyelike feature observed on a WSR-88D at a range of 62 $\mathrm{km}$ was shown by Lemon and Umscheid (2008), who called the signature a reflectivity vortex hole. Wood et al. (2005) suggested that finer-resolution (i.e., 250-m spacing in range and $0.5^{\circ}$ spacing in azimuth) WSR$88 \mathrm{D}$ measurements would yield increased resolution of such eyes at the center of tornadoes out to ranges of about $100 \mathrm{~km}$. Operational WSR-88Ds transitioned to such a $250-\mathrm{m}$ range, $0.5^{\circ}$ azimuth super-resolution grid spacing in 2008 (Seo and Krajewski 2010). Superresolution data were being produced by KLNX on 11 August 2011.

\section{Data and methods}

Archived level-II, single-polarization radar data from KLNX were obtained from the National Climatic Data Center (NCDC) and utilized to analyze the tornadic supercell near Purdum, Nebraska, on $11 \mathrm{Au}-$ gust 2011. Constant-elevation and three-dimensional radar imagery was analyzed using GR2Analyst software (www.grlevelx.com/gr2analyst 2/). In addition, the environment near the supercell was assessed with a Rapid Update Cycle (RUC) sounding that used the Storm Prediction Center analysis scheme (Bothwell et al. 2002).

In order to provide additional examples of reflectivity vortex holes sampled by polarimetric WSR88Ds, archived level-II radar data associated with four other tornadoes also were obtained from NCDC. The Wichita, Kansas (KICT), data from 19 May 2013, Denver, Colorado (KFTG), data from 18 June 2013, and the Twin Lakes, Oklahoma (KTLX), data from 20 May 2013 and 31 May 2013 were all analyzed using GR2Analyst.

\section{Analysis of the 11 August 2011 event}

The supercell that eventually produced the vortex hole developed near 0100 UTC 12 August 2011. The storm produced numerous operator- and algorithm- 
defined tornadic vortex signatures (TVSs) as it moved southeast in an environment characterized by $100-\mathrm{hPa}$ mixed-layer convective available potential energy of $1692 \mathrm{~J} \mathrm{~kg}^{-1}$ and $0-1-\mathrm{km}$ storm-relative helicity of 502 $\mathrm{m}^{2} \mathrm{~s}^{-2}$ [based on an objectively analyzed proximity sounding from the RUC (not shown)]. No tornadoes were verified during the first portion of the supercell's life cycle, but hail up to the size of baseballs occurred (NCDC 2011). Distinct features characteristic of an intense supercell, including a hook echo with a strong inflow-side reflectivity gradient and bounded weak echo region (BWER; Lemon 1977), were observed by KLNX between 0117 and 0248 UTC (not shown).

Beginning with the 0253 UTC radar scan, a distinct reflectivity minimum (with values $<50 \mathrm{dBZ}$ ) was observed within the hook echo in the low- and midlevels of the storm (Fig. 2a). When first detected, the reflectivity minimum (that was separate from the supercell's BWER) extended to an altitude of approximately $4.2 \mathrm{~km}$ above ground level (AGL), though it was most prominent near $0.3 \mathrm{~km}$ AGL in the $0.5^{\circ}$ reflectivity data. An EF0 tornado occurred $1.6 \mathrm{~km}(0.9$ $\mathrm{n}$ mi) west-northwest of Purdum, Nebraska, at 0253 UTC and damaged large elm trees and snapped off four power poles (NCDC 2011). The rotational velocity in the $0.5^{\circ}$ storm-relative velocity data, based on observed storm motion at the time of the tornado, was near $33 \mathrm{~m} \mathrm{~s}^{-1}$ (64 kt). The rotational velocity signature corresponded in location to the reflectivity minimum. By 0258 UTC, the eye-like appearance of the hook echo became even more prominent as reflectivity within the hole remained $<30 \mathrm{dBZ}$ while the reflectivity surrounding it underwent a notable increase (Fig. 2b). The eye was approximately $0.83-\mathrm{km}(0.45-\mathrm{n} \mathrm{mi})$ wide. The reflectivity minimum was detectable up to $8.7 \mathrm{~km}$ AGL at 0258 UTC, and at some levels the reflectivity within the hole was $<20 \mathrm{dBZ}$. Rotational velocity increased further [with a peak value of $38 \mathrm{~m} \mathrm{~s}^{-1}$ (74 kt) at $0.5^{\circ}$, and the rotational signature was juxtaposed with the reflectivity minimum at all levels. Low spectrum width values were present in the eye, with higher values $>5 \mathrm{~m} \mathrm{~s}^{-1}(10 \mathrm{kt})$ on its periphery (not shown). The TVS had propagated into a rural, inaccessible area by 0258 UTC, so no tornado was officially recorded in NOAA Storm Data during that or subsequent radar volume scans. However, the reflectivity minimum in the hook echo was still easily detectable at 0302 UTC (Fig. 2c), even though its depth decreased substantially to only $2.1 \mathrm{~km}$ AGL. Rotational velocity also decreased slightly with a maximum value of $33 \mathrm{~m} \mathrm{~s}^{-1}$ (64 $\mathrm{kt})$ at $0.5^{\circ}$. Interestingly, rotational velocity continued

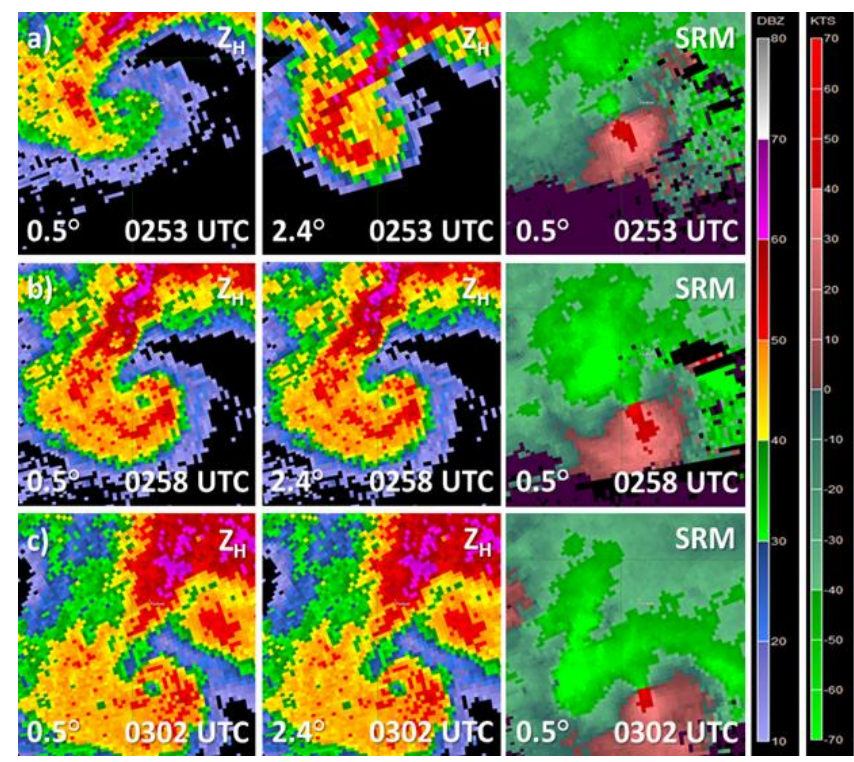

Figure 2. Images from the KLNX WSR-88D on 12 August 2011: $0.5^{\circ}$ reflectivity $\left(Z_{H}\right.$, column 1$) ; 2.4^{\circ}$ reflectivity (column 2 ); and $0.5^{\circ}$ storm-relative velocity (SRV, column 3 ). The spatial extent for all columns along the $x$ axis is $31.2 \mathrm{~km}(16.8 \mathrm{n} \mathrm{mi})$ and for the $y$ axis is $30.5 \mathrm{~km}$ (16.5 n mi). Times are (a) $0253 \mathrm{UTC}$, (b) 0258 UTC, and (c) 0302 UTC.

diminishing after 0302 UTC, and while the reflectivity minimum was still detectable at 0307 UTC, both that feature and discernible low- to midlevel rotational velocity disappeared concurrently by 0311 UTC (not shown).

Lemon and Umscheid (2008) - in describing the Greensburg, Kansas, storm using WSR-88D datastated that a vortex hole is a column of reflectivity $<55$ $\mathrm{dBZ}$ extending through stronger echo that corresponds to a tornado cyclone signature, and which is separate from the BWER. The feature observed in the hook echo of the 11 August 2011 supercell meets these criteria. However, the vortex hole in the Greensburg, Kansas, storm was not detectable at low levels. In that regard, the vortex hole detected near Purdum, Nebras$\mathrm{ka}$, was more like the eye-like features detected in high-resolution radar data. Remarkably, the depth of the vortex hole on 11 August 2011 mirrored the magnitude of the rotational velocity signature with which it corresponded. That is, the depth of the vortex hole increased as low-level rotation intensified, reached a maximum altitude when the low-level rotational velocity was at its strongest, and then decreased along with the low-level rotation.

Another way of viewing the vortex hole on 11 August 2011 is through the three-dimensional radar display available from the GR2Analyst software. As seen in Fig. 3, the column making up the vortex hole 

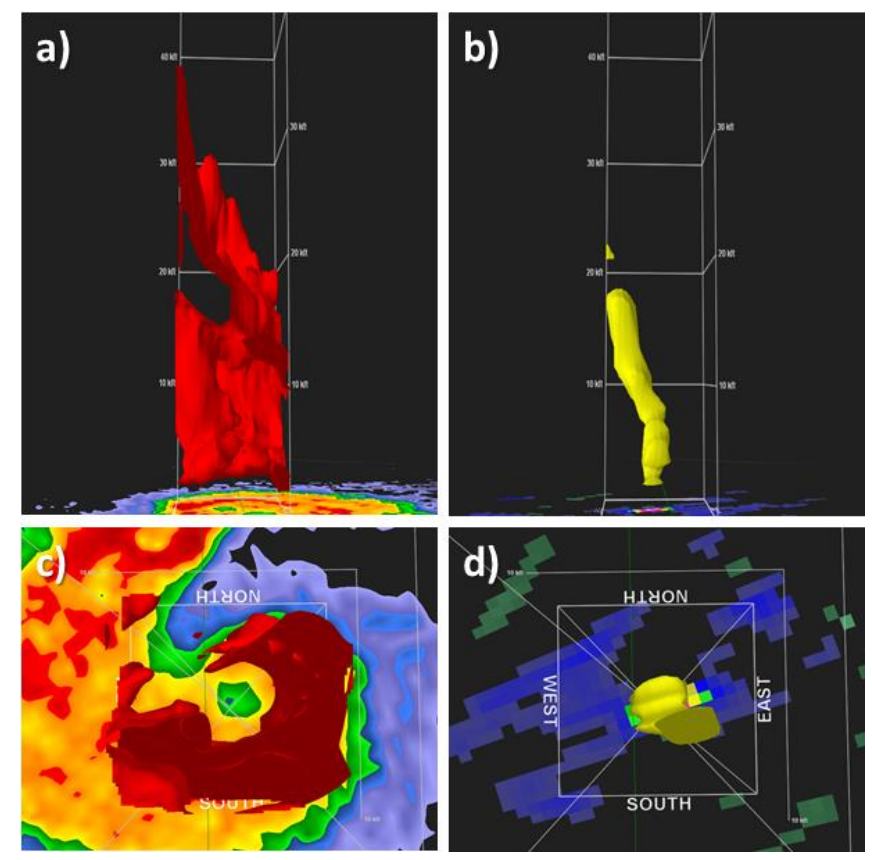

Figure 3. KLNX WSR-88D data displayed using 3-dimensional isosurfaces at $0258 \mathrm{UTC}$ for (a) 55-dBZ reflectivity $\left(Z_{H}\right)$, (b) 2.0 normalized rotation, (c) 55-dBZ reflectivity (looking downward), and (d) 2.0 normalized rotation (looking downward).

extended to a significant altitude, was tilted, and provided the dramatic appearance of an open eye even when looking downward through the hook echo. Values of normalized rotation from GR2Analyst [and described by Lemon and Umscheid (2008)] of $>2.0$ displayed on an isosurface closely matched the vortex hole, as well (Fig. 3). This provides further evidence that the feature was indeed associated with the tornado cyclone.

\section{Discussion of four other cases}

Warning meteorologists working the event at the North Platte, Nebraska, National Weather Service office had not previously encountered a reflectivity vortex hole as prominent as the one associated with the tornadic supercell near Purdum, Nebraska, but it was not clear if the feature was particularly rare to see on a WSR-88D operating in super-resolution mode. Thus, four prominent tornadoes in close proximity to WSR88Ds during 2013 were arbitrarily chosen for review in order to help provide some insight into the rarity of reflectivity vortex holes. Those four events were an EF2 tornado near Wichita, Kansas, on 19 May 2013, the EF5 Newcastle-Moore, Oklahoma, tornado on 20 May 2013, and the EF3-rated tornado near El Reno, Oklahoma, on 31 May 2013 (NCDC 2013a), as well as an EF1 tornado near Denver, Colorado, on 18 June
2013 (NCDC 2013b). All four cases revealed at least brief reflectivity vortex holes, although none of the signatures were as well-defined or long-lasting as the one near Purdum, Nebraska. Polarimetric radar information was available for all four cases and provided a comparison with TDSs such as differential reflectivity $\left(Z_{\mathrm{DR}}\right)$ values $<0.5 \mathrm{~dB}$ and correlation coefficient $\left(\rho_{\mathrm{hv}}\right)$ values $<0.8$ (Ryzhkov et al. 2005). A minimum reflectivity threshold of $20 \mathrm{dBZ}$ was considered for classification as a TDS [Warning Decision Training Branch (WDTB 2013)].

A supercell produced a tornado southwest of Wichita, Kansas, from 2137 to 2148 UTC on 19 May 2013 (NCDC 2013a). A reflectivity minimum with values $<30 \mathrm{dBZ}$ (surrounded by echoes $>50 \mathrm{dBZ}$ ) was apparent in the hook echo of the storm at $0.5^{\circ}$ prior to tornadogenesis (at 2031 UTC). However, no polarimetric TDSs were detected at that time (not shown). During the 2036 UTC radar scan an area of reflectivity $<50 \mathrm{dBZ}$ was still present in the hook echo at $0.5^{\circ}$, but the feature had grown upward and was much more defined aloft, with reflectivity $<30 \mathrm{dBZ}$ colocated with the maximum in rotational velocity between 1.0 and $2.1 \mathrm{~km} \mathrm{AGL}$ [the maximum altitude of the radar beam at a distance of $5.9 \mathrm{~km}(3.2 \mathrm{n} \mathrm{mi})$ from the radar]. Polarimetric data showed $Z_{\mathrm{DR}}$ as low as $-0.4 \mathrm{~dB}$ and $\rho_{\mathrm{hv}}<0.8$ co-located with the relative minimum in reflectivity and a rotational velocity of $41 \mathrm{~m}$ $\mathrm{s}^{-1}$ (80 kt) near $0.1 \mathrm{~km}$ AGL at 2036 UTC (Fig. 4). The vortex hole was still detectable at 2040 UTC, but was weaker (as were the rotational velocities; not shown).

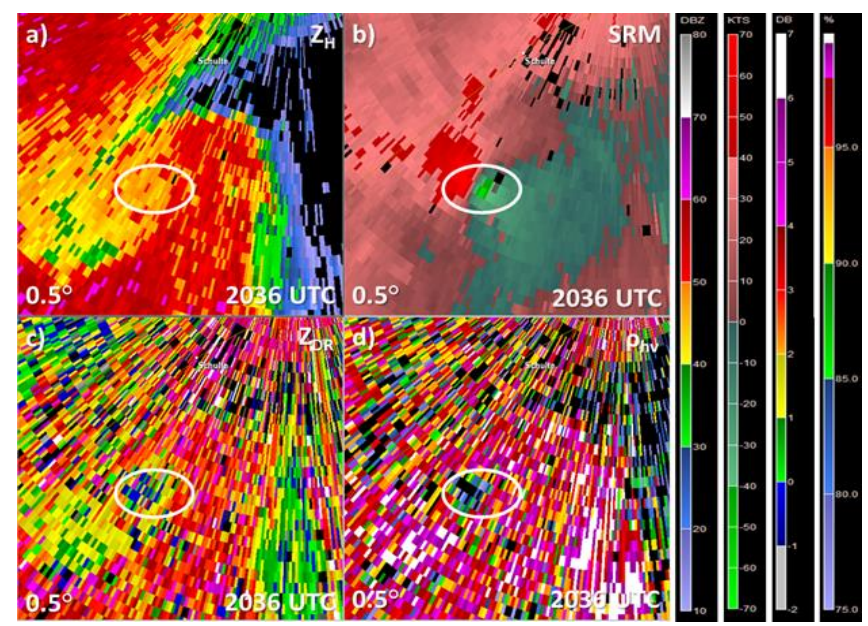

Figure 4. Images from the KICT WSR-88D at 2036 UTC 19 May 2013: (a) $0.5^{\circ}$ reflectivity $\left(Z_{H}\right)$, (b) $0.5^{\circ}$ storm-relative velocity (SRV), (c) $0.5^{\circ}$ differential reflectivity $\left(Z_{\mathrm{DR}}\right)$, and (d) $0.5^{\circ}$ correlation coefficient $\left(\rho_{\mathrm{hv}}\right)$. The spatial extent for all columns along the $x$ axis is $7.2 \mathrm{~km}(3.9 \mathrm{n} \mathrm{mi})$ and for the $y$ axis is $8.1 \mathrm{~km}(4.4 \mathrm{n} \mathrm{mi})$. The location of the reflectivity vortex hole is highlighted in each panel by a white oval. 
The Newcastle-Moore, Oklahoma, tornado began at 1956 UTC 20 May 2013 (NCDC 2013a), and KTLX revealed reflectivity $\angle 30 \mathrm{dBZ}$ in the hook echo of the storm coincident with increasing low-level rotation at a distance of about $30.0 \mathrm{~km}(16.0 \mathrm{n} \mathrm{mi})$ at 1955 UTC. Once damage from the violent tornado increased, the hook echo became filled with reflectivity $>60 \mathrm{dBZ}$ at $0.5^{\circ}$ by 2003 UTC (Fig. 5). Polarimetric TDSs also were detected by KTLX once tornado damage began (not shown). Even though a vortex hole was not present near the surface once debris filled the hook echo, one was still readily apparent aloft. Reflectivity in the vicinity of the TVS was $<45 \mathrm{dBZ}$ beginning at an altitude of $3.9 \mathrm{~km}$ AGL, and it dropped to $<25 \mathrm{dBZ}$ at $8.9 \mathrm{~km}$, where the signature had its maximum width of $0.96 \mathrm{~km}$ or $0.52 \mathrm{n} \mathrm{mi} \mathrm{(Fig.} \mathrm{6).} \mathrm{On} 31$ May 2013, KTLX sampled another reflectivity vortex hole at a distance of $65 \mathrm{~km}(36 \mathrm{n} \mathrm{mi})$ with the tornadoproducing supercell near El Reno, Oklahoma. The reflectivity vortex hole was only briefly and weakly defined on $0.5^{\circ}$ reflectivity when the tornado first began (prior to the existence of an obvious TDS; not shown), but the feature grew upward with time and showed up as a distinct eye near $1.6 \mathrm{~km}$ AGL at $1.4^{\circ}$ by 2314 UTC, by which time a polarimetric TDS also was apparent with low values of $Z_{\mathrm{DR}}$ and $\rho_{\mathrm{hv}}$ (Fig. 7). The reflectivity vortex hole with the El Reno tornado was not especially large with a maximum width of only $0.5 \mathrm{~km}(0.3 \mathrm{n} \mathrm{mi})$ at $1.4^{\circ}$. Damage survey results from NCDC (2013b) reported that the tornado had a width of $4.3 \mathrm{~km}(2.3 \mathrm{n} \mathrm{mi})$, so apparently at least in this case there was no consistency between the width of the reflectivity vortex hole and the tornado. The marginal nature of the reflectivity vortex signature may have been partly the result of distance from the radar, which was near the maximum distance Wood et al. (2005) suggested that eyes would be viewable using super-resolution radar data.

The KFTG radar observed a distinct reflectivity vortex hole with a tornado that did minor damage on the property of the Denver, Colorado, airport on 18 June 2013 (NCDC 2013b), with $0.5^{\circ}$ reflectivity <20 $\mathrm{dBZ}$ co-located with a rotational velocity of $23 \mathrm{~m} \mathrm{~s}^{-1}$ (45 kt) near $0.1 \mathrm{~km} \mathrm{AGL}$ at 2028 UTC (Fig. 8). The maximum width of the vortex hole was $0.6 \mathrm{~km}(0.3 \mathrm{n}$ $\mathrm{mi})$, but it was detectable only after the tornado was on the ground for several minutes. Polarimetric fields in Fig. 8 were noisy and no TDS was apparent. The low reflectivity in the hook echo may have contributed to the lack of a detectable polarimetric TDS because it was below the 20-dBZ minimum criterion for classifi-

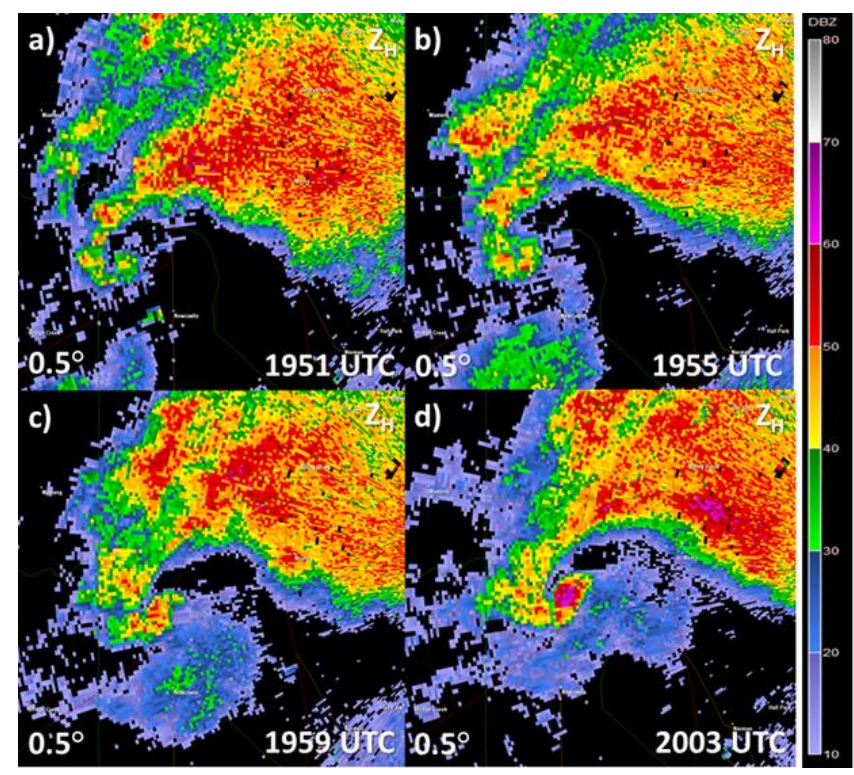

Figure 5. Images of $0.5^{\circ}$ reflectivity $\left(Z_{H}\right)$ from the KTLX WSR88D on 20 May 2013 at (a) 1951 UTC, (b) 1955 UTC, (c) 1959 UTC, and (d) 2003 UTC. The spatial extent for all columns along the $x$ axis is $33.7 \mathrm{~km}(18.2 \mathrm{n} \mathrm{mi})$ and for the $y$ axis is $28.5 \mathrm{~km}(15.4$ $\mathrm{n} \mathrm{mi).}$

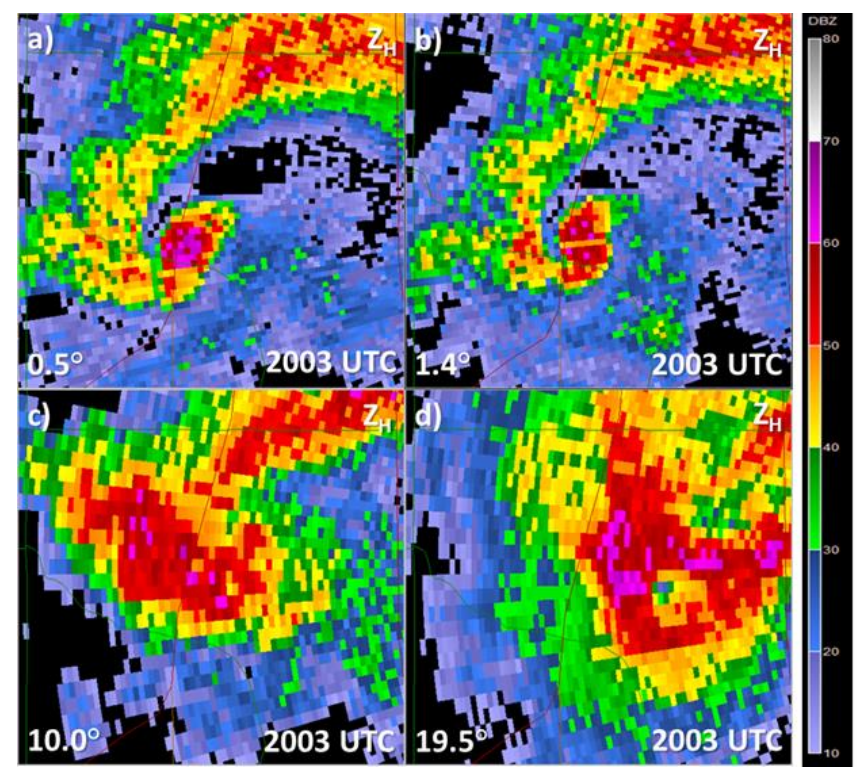

Figure 6. Images of reflectivity $\left(Z_{H}\right)$ from the KTLX WSR-88D at 2003 UTC 20 May 2013 at (a) $0.5^{\circ}$, (b) $1.5^{\circ}$, (c) $10.0^{\circ}$, and (d) $19.5^{\circ}$. The spatial extent for all columns along the $x$ axis is 16.5 $\mathrm{km}(8.9 \mathrm{n} \mathrm{mi})$ and for the $y$ axis is $14.3 \mathrm{~km}(7.7 \mathrm{n} \mathrm{mi})$.

cation as one given by the WDTB (2013).

The presence of at least brief reflectivity vortex holes in each of the individual cases composing the small, arbitrary sample from May and June 2013 suggests that they may not be particularly rare. Like the Purdum, Nebraska, vortex hole, the reflectivity features in three of four cases from May and June 2013 


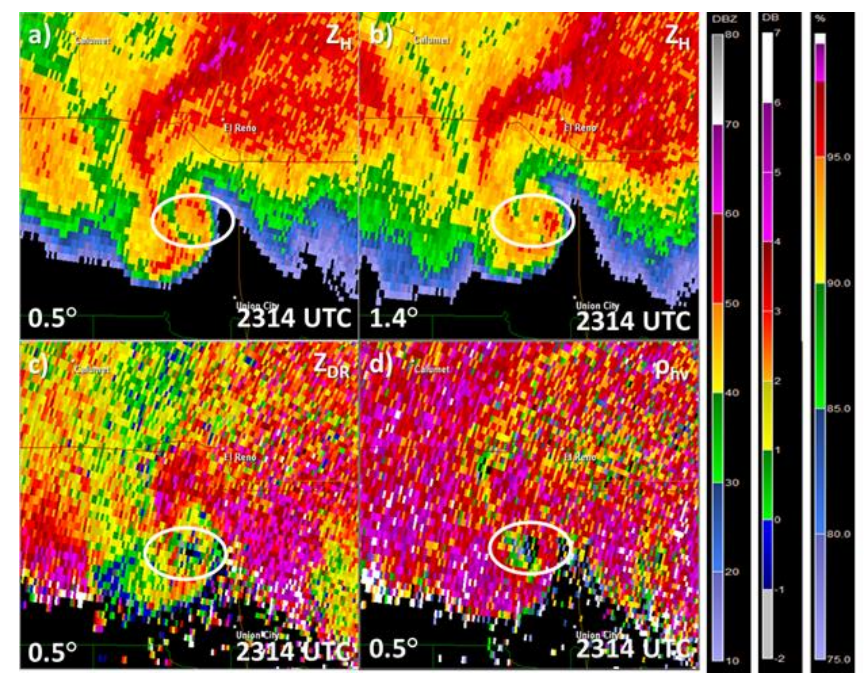

Figure 7. Images from the KTLX WSR-88D at 2314 UTC 31 May 2013: (a) $0.5^{\circ}$ reflectivity $\left(Z_{H}\right)$, (b) $1.5^{\circ}$ reflectivity $\left(Z_{H}\right)$, (c) $0.5^{\circ}$ differential reflectivity $\left(Z_{\mathrm{DR}}\right)$, and (d) $0.5^{\circ}$ correlation coefficient $\left(\rho_{\text {hv }}\right)$. The spatial extent for all columns along the $x$ axis is $32.3 \mathrm{~km}$ $(17.7 \mathrm{mi})$ and for the $y$ axis is $28.3 \mathrm{~km}(15.3 \mathrm{n} \mathrm{mi})$. The location of the reflectivity vortex hole is highlighted in each panel by a white oval.

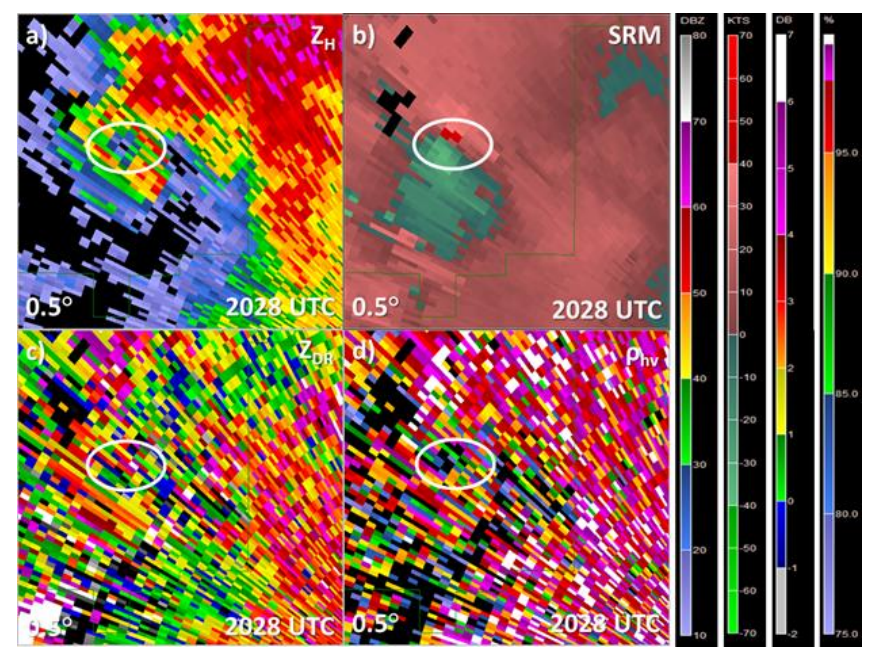

Figure 8. As in Fig. 4, except for the KFTG WSR-88D at 2028 UTC 18 June 2013 and the spatial extent for all columns along the $x$ axis is $8.5 \mathrm{~km}(4.6 \mathrm{n} \mathrm{mi})$ and for the $y$ axis is $7.0 \mathrm{~km}(3.8 \mathrm{n} \mathrm{mi})$.

grew upward with time. In one of the cases (the Wichita, Kansas, event), the reflectivity vortex hole preceded the tornado touchdown by several minutes. The detection of a reflectivity vortex hole may therefore add confidence to the development or presence of a tornado. However, it is not clear from the present study how often they may occur without an accompanying tornado. Bluestein (1985) documented large vertical holes in the middle of wall clouds associated with TVSs that did not produce tornadoes, so plausibly not all reflectivity vortex holes are associated with tor- nadogenesis. In that regard, meteorologists are encouraged to use any observations of reflectivity vortex holes alongside an analysis of velocity and near-storm environmental data in order to establish the likelihood of a tornado with an eye-like feature in radar imagery.

Polarimetric radar data were not available from KLNX in 2011, but the small sample of cases from 2013 that were analyzed using other WSR-88Ds provided insight into the use of polarimetric fields in the presence of reflectivity vortex holes. Specifically, the analyzed polarimetric TDSs suggested that they may be preceded by reflectivity vortex holes. Moreover, in one instance the criteria for a polarimetric TDS were not met owing to low reflectivity-resulting from a lack of large debris or a lack of a large concentration of debris - but a vortex hole still was present. In that manner, recognition of reflectivity vortex holes may be used in tandem with polarimetric TDSs by meteorologists in their decision-making process. For instance, given the potential for a reflectivity vortex hole to immediately precede a TDS, meteorologists may anticipate the possibility of imminent tornadogenesis and more carefully scrutinize polarimetric data in subsequent radar scans. Similarly, in cases where a TDS lingers after a tornado has lifted, such as that shown in Schultz et al. (2012), warning meteorologists may have some indication that the tornado is no longer occurring if an observed vortex hole weakens (especially aloft where higher reflectivity from debris is less likely to obscure the hole).

\section{Conclusions}

A vortex hole was observed at close range to the KLNX WSR-88D on 11 August 2011. The vortex hole was notable even at low altitudes and its depth closely mimicked the strength of low-level rotation in the hook echo. Even though the vortex hole was at its peak depth while over a rural, inaccessible area that prevented documentation of a tornado during that portion of its life cycle, tornado damage was confirmed during a previous volume scan showing the vortex hole. Based on a small sample of cases from 2013, reflectivity vortex holes may not be especially rare in superresolution WSR-88D data, and when present, they likely are associated with tornado cyclones. Care needs to be taken to ensure that a reflectivity feature deemed a vortex hole is indeed separate from a BWER and coincident with rotational velocity signatures. However, when these criteria are met in a near-storm environment favoring tornadogenesis, confidence in 
tornado development or occurrence may be heightened. Reflectivity vortex holes likely grow upward with time in most cases and may precede tornadoes by several minutes. Although they do not provide direct evidence of a tornado, reflectivity vortex holes can supplement polarimetric TDSs to aide meteorologists in detecting tornadoes and specifying their location.

Acknowledgments. The author is grateful for the thought-provoking and very helpful reviews and assistance of Marc Singer, Keith Meier, John Stoppkotte, Jon Zeitler, and two anonymous reviewers. The author also thanks Jared Guyer for providing RUC sounding data.

\section{REFERENCES}

Bluestein, H. B., 1985: Wall clouds with eyes. Mon. Wea. Rev., 113, 1081-1085, CrossRef.

Bothwell, P. D., J. A. Hart, and R. L. Thompson, 2002: An integrated three-dimensional objective analysis scheme in use at the Storm Prediction Center. Preprints, 21st Conf. on Severe Local Storms, San Antonio, TX, Amer. Meteor. Soc., J117-J120. [Available online at ams.confex.com/ams/pdfpapers/47482.pdf.]

Browning, K. A., 1965: Comments on "Formation and Steering Mechanisms of Tornado Cyclones and Associated Hook Echoes." Mon. Wea. Rev., 93, 639641, CrossRef.

Bunkers, M. J., and M. A. Baxter, 2011: Radar tornadic debris signatures on 27 April 2011. Electronic J. Operational Meteor., 12 (7), 1-6. [Available online at www.nwas.org/ej/pdf/2011-ION1.pdf.]

Burgess, D. W., M. A. Magsig, J. Wurman, D. C. Dowell, and Y. Richardson, 2002: Radar observations of the 3 May 1999 Oklahoma City tornado. Wea. Forecasting, 17, 456-471, CrossRef.

Dowell, D. C., C. R. Alexander, J. M. Wurman, and L. J. Wicker, 2005: Centrifuging of hydrometeors and debris in tornadoes: Radar-reflectivity patterns and windmeasurement errors. Mon. Wea. Rev., 133, 1501-1524, CrossRef.

Fujita, T., 1958: Mesoanalysis of the Illinois tornadoes of 9 April 1953. J. Meteor., 15, 288-296, CrossRef.

1965a: Formation and steering mechanisms of tornado cyclones and associated hook echoes. Mon. Wea. Rev., 93, 67-78, CrossRef. 1965b: Reply. Mon. Wea. Rev., 93, 640-643, CrossRef.

, 1981: Tornadoes and downbursts in the context of generalized planetary scales. J. Atmos. Sci., 38, 15111534, CrossRef.

Lemon, L. R., 1977: New severe thunderstorm radar identification techniques and warning criteria: A preliminary report. NOAA Tech. Memo., NWS NSSFC-1, 60 pp. [Available from NOAA Central Library, 1315 East-West Highway, Silver Spring, MD 20910.]

, and M. Umscheid, 2008: The Greensburg, Kansas tornadic storm: A storm of extremes. Preprints, 24th Conf. on Severe Local Storms, Savannah, GA, Amer. Meteor. Soc., 2.4. [Available online at ams.confex.com/ ams/pdfpapers/141811.pdf.]

NCDC, 2011: Storm Data, 53 (8), 758 pp. [Available online at www.ncdc.noaa.gov/IPS/sd/sd.html.] , 2013a: Storm Data, 55 (5), 684 pp. [Available online at www.ncdc.noaa.gov/IPS/sd/sd.html.] , 2013b: Storm Data, 55 (6), 882 pp. [Available online at www.ncdc.noaa.gov/IPS/sd/sd.html.]

Ryzhkov, A. V., T. J. Schuur, D. W. Burgess, and D. S. Zrnic, 2005: Polarimetric tornado detection. J. Appl. Meteor., 44, 557-570, CrossRef.

Schultz, C. J., and Coauthors, 2012: Dual-polarization tornadic debris signatures. Part II: Comparisons and caveats. Electronic J. Operational Meteor., 13 (10), 138-150. [Available online at www.nwas.org/ej/pdf/ 2012-EJ10.pdf.]

Seo, B-C., and W. F. Krajewski, 2010: Scale dependence of radar rainfall uncertainty: Initial evaluation of NEXRAD's new super-resolution data for hydrologic applications. J. Hydrometeor, 11, 1191-1198, CrossRef.

Wakimoto, R. M., and B. E. Martner, 1992: Observations of a Colorado tornado. Part II: Combined photogrammetric and Doppler radar analysis. Mon. Wea. Rev., 120, 522-543, CrossRef.

WDTB, cited 2013: Dual-polarization radar training. [Available online at www.wdtb.noaa.gov/courses/ dualpol/index.html.]

Wood, V. T., R. A. Brown, and D. C. Dowell, 2005: Simulated WSR-88D measurements of low-reflectivity eyes associated with tornadoes. Preprints, 32nd Conf. on Radar Meteor., Albuquerque, NM, Amer. Meteor. Soc., P15R.6. [Available online at ams.confex.com/ ams/pdfpapers/95820.pdf.] 